\title{
HRM analysis targeting ITS1 and matK loci as potential DNA mini-barcodes for the authentication of Hypericum perforatum and Hypericum androsaemum in herbal infusions
}

\author{
Joana Costa a, Bruna Campos a, Joana S. Amaral a, b, M. Eugénia Nunes c, \\ M. Beatriz P.P. Oliveira ${ }^{a}$, Isabel Mafra ${ }^{\text {a, }}{ }^{*}$ \\ ${ }^{a}$ REQUIMTE-LAQV, Faculdade de Farmácia, Universidade do Porto, Rua de Jorge Viterbo Ferreira, 228, 4050-313 Porto, Portugal \\ ${ }^{\mathrm{b}}$ Instituto Politécnico de Bragança, Campus de Sta. Apolónia, 5301-857 Bragança, Portugal

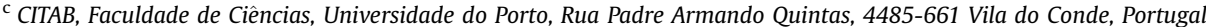

\section{A R T I C L E I N F O}

\section{Article history:}

Received 5 August 2015

Received in revised form 24 September 2015

Accepted 25 September 2015

Available online 30 September 2015

\section{Keywords:}

Medicinal plants

DNA-barcoding

Real-time PCR

High resolution melting analysis

Species detection

Authenticity

\begin{abstract}
A B S T R A C T
Hypericum species are among the medicinal plants that are being increasingly used due to their reported health benefits. Hypericum perforatum (St. John's wort) is well known for its anti-inflammatory, antidepressive and anti-viral properties, as well as a healing agent. In Portuguese folk medicine, Hypericum androsaemum (Hipericão do Gerês) is largely used for its hepatic protective and diuretic properties. This work aimed at searching the potential use of two DNA mini-barcode candidates (ITS1 and matK) for the authentication of $H$. perforatum and $H$. androsaemum in herbal infusions. The sequencing results from ITS1 and matK regions were the basis for the development of species-specific PCR and real-time PCR assays coupled to High Resolution Melting (HRM) analysis, as simple approaches for the reliable discrimination of both species. The barcode regions were successful in the species-specific PCR identification of each target. ITS1 region revealed some intra-species variability from sequencing results, which compromises HRM analysis, while matK showed to be an adequate mini-barcode for the differentiation of both species by real-time PCR coupled to HRM analysis. The assays were effectively applied to commercial herbal infusions, enabling the consistent identification of two labels with non-declared Hypericum species.
\end{abstract}

๑) 2015 Elsevier Ltd. All rights reserved.

\section{Introduction}

Hypericum L. (Hypericaceae) is a large genus including approximately 450 species, from which 27 have been described to possess medicinal properties (Penso, 1983). Among those, Hypericum perforatum, also known as St. John's wort, is considered to be the most known and economically important Hypericum species due to its widespread use as a medicinal plant for the treatment of anxiety, depression and topical wounds (see review Guedes, Franklin, and Fernandes-Ferreira (2012)). Over the past decades, the consumption of St. John's wort has gained increased popularity for the symptomatic treatment of minor depressive episodes (European Medicine Agency, 2009; Sarris, 2007), being its phytotherapeutic activity demonstrated in different clinical trials, where it was found

\footnotetext{
* Corresponding author.

E-mail address: isabel.mafra@ff.up.pt (I. Mafra).
}

to be superior than the placebo and as effective as the commonly prescribed anti-depressive drugs (Linde et al., 1996; Schrader, Meier, \& Brattstrom, 1998; Woelk, 2000). Currently, it is considered as one of the most requested and top selling herbal preparations in developed countries, being frequently included in traditional herbal medicines and plant food supplements (Egan, Hodgkins, Shepherd, Timotijevic, \& Raats, 2011; Ernst \& Izzo, 2003; Franz, Chizzola, Novak, \& Sponza, 2011).

Other Hypericum species are also frequently used in folk medicine, namely Hypericum androsaemum (known in Portugal as Hipericão do Gerês), whose aerial parts are used for their diuretic and hepatoprotective effects (Almeida, Fernandes, Lima, Costa, \& Bahia, 2009; Valentão et al., 2003, 2004). Since H. androsaemum is less abundant and simultaneously very popular in Portugal, its price is generally higher than the one of St. John's wort (Valentão et al., 2003). Due to the high demand of both species and considering that they are commonly sold after being dried and fragmented/powdered, these botanicals are particularly prone to 
be adulterated by the intentional substitution with other cheaper plants. Moreover, owing to the similarity of Hypericum species, unintentional swap of plants caused by the misidentification of wild collected specimens can also occur. For these reasons, there is an increasing need for reliable methods to authenticate both, raw botanical materials and final commercialised herbal products.

So far, different analytical methodologies, mainly based on chromatographic techniques, have been proposed for quality control purposes and authentication of $H$. perforatum. The antidepressive effect was firstly attributed to its composition in naphthodianthrones, namely hypericins and its derivatives (Butterweck, Petereit, Winterhoff, \& Nahrstedt, 1998), though more recently, other major secondary metabolites, such as flavonoids and phloroglucinols, have also been suggested to contribute to its bioactivity (Butterweck \& Schmidt, 2007; Russo et al., 2014). The use of these bioactive substances as marker compounds for $H$. perforatum (Conforti et al., 2005; Hosni, Msaâda, Taârit, Hammami, \& Marzouk, 2010), in particular the hypericins, as it is only found in Hypericum species (Kitanov, 2001), has been suggested by different research studies, being also included in the European Pharmacopeia monographs for $H$. perforatum drug and extract. However, hypericins, phloroglucinols and flavonoids have been described in other Hypericum species besides St. John's wort (Linde et al., 1996; Valentão et al., 2003), making its use as marker compounds not adequate. Moreover, the amount of plant phytochemicals might vary depending on the edaphoclimatic conditions, part of the plant and harvest time, among other factors (Büter, Orlacchio, Soldati, \& Berger, 1998; Nahrstedt \& Butterweck, 1997; Poutaraud \& Girardin, 2004).

In opposition to chemical profiling, the use of molecular biology techniques has proved to be well suited for unequivocal plant species identification since DNA molecules are found in all tissues and are not affected by external or physiological plant conditions (Sucher \& Carles, 2008). Among different DNA-based techniques, the use of barcodes has been recently proposed as a powerful pharmacognostic tool for the identification of medicinal plants and their adulterants at species level (Chen et al., 2010; Newmaster, Grguric, Shanmughanandhan, Ramalingam, \& Ragupathy, 2013; Techen, Parveen, Pan, \& Khan, 2014; Zhang, Yang, Jiang, Lizhen, \& Zhou, 2014). DNA barcoding relies on sequence variation within a short and standardised region of the genome, designated as a "barcode", to provide accurate species identification (Hebert, Cywinska, Ball, \& deWaard, 2003). However, DNA barcoding covers the amplification and sequencing of large DNA fragments (400-800 bp), which represents a major drawback for the analysis of highly processed samples. When analysing samples with degraded DNA, such as processed medicinal plants, poorly preserved plants and/or stored for a long period of time, DNA barcodes are probably not the best target sequences. In such cases, the use of species-specific primers based on barcodes, but targeting small size amplicons (e.g. DNA mini-barcodes) has been successfully applied for species identification (Fields, Abercrombie, Eng, Feldheim, \& Chapman, 2015; Hajibabaei \& McKenna, 2012; Little, 2014). The recent approach of high resolution melting (HRM) analysis coupled to specific barcodes represents a potential cost-effective tool to detect small nucleotide differences without requiring further sequencing (Xanthopoulou et al., 2016).

This work aimed at proposing a practical, specific and highthroughput tool to identify and differentiate two Hypericum species, namely $H$. perforatum and $H$. androsaemum. For that purpose, two candidate DNA barcode loci (ITS1 and matK) were targeted by real-time PCR coupled to HRM analysis. The proposed methodology was further applied to authenticate different commercial herbal medicines labelled as containing Hypericum species.

\section{Material and methods}

\subsection{Sample preparation}

Voucher seeds from $H$. perforatum $(n=3)$ and $H$. androsaemum $(n=2)$ were gently provided by USDA-ARS Germplasm Resources Information Network (Beltsville, MD, USA) and by the Royal Botanic Gardens (RBG, Kew, Ardingly, UK). For cross-reactivity assays, 37 medicinal plant species were provided by National and International Germplasm Banks or obtained at herbal stores (Cymbopogon citratus (DC.) Stapf, Foeniculum vulgare Mill, Taraxacum officinales F.H. Wigg., Equisetum arvense L., Melissa officinalis L., Matricaria chamomilla L., Camellia sinensis (L.) Kuntze, Salvia officinalis L., Mentha piperita, Cochlospermum angolense Welw. ex Oliv., Pterospartum tridentatum L., Malva sylvestris L., Senna alexandrina Mill., Tilia spp., Arctostaphylos uva-ursi (L.) Spreng., Geranium robertianum L., Cynara scolymus L., Passiflora incarnata L., Peumus boldus Molina, Verbena officinalis L., Crataegus monogyna Jacq, Valeriana officinalis L., Silybum marianum (L.) Gaertn., Origanum vulgare L., Ocimum basilicum L., Coriandrum sativum L., Curcuma longa L., Prunus avium L., Aloysia citrodora Paláu, Eucalyptus obliqua L'Hér., Ginkgo biloba L., Aesculus hippocastanum L., Vitis vinífera L., Rosmarinus officinalis L., Olea europaea L., Ficus carica L., Juglans regia L.). Herbal infusion samples $(n=13)$ were acquired at the retail market or at specialised herbal stores. Seeds were grounded with mortar and pestle, while herbal infusions and medicinal plants, mostly consisting of leaf material, were grounded and homogenised separately in a laboratory knife mill Grindomix GM200 (Retsch, Haan, Germany). All containers and material used during this procedure were previously treated with DNA decontamination solution (DNA-ExitusPlus $^{\mathrm{TM}}$, AppliChem, Darmstadt, Germany).

\subsection{DNA extraction}

In this work, two different extraction procedures were used, namely the CTAB-PVP method and Nucleospin Plant kit (Macherey-Nagel, Düren, Germany), respectively for the DNA extraction from leaves and seeds. The CTAB-PVP method was performed as described by Costa, Melo, Santos, Oliveira, and Mafra (2015) using an initial amount of $100 \mathrm{mg}$ of ground leaf material.

DNA from $100 \mathrm{mg}$ of ground seeds was extracted with the commercial DNA extraction kit Nucleospin Plant II (Macherey-Nagel, Düren, Germany), according to manufacturer's instructions with minor alterations. Briefly, DNA extraction followed the protocol using buffer PL2 (pre-heated at $65^{\circ} \mathrm{C}$ ) and an incubation of $1 \mathrm{~h}$ at $65{ }^{\circ} \mathrm{C}$ with continuous stirring $(1000 \mathrm{rpm})$. After incubation, the protocol was performed according to manufacturer's instructions. DNA extracts were immediately kept at $-20^{\circ} \mathrm{C}$ until further analysis.

\subsection{Quality of DNA}

Yield and purity of extracts were assessed by UV spectrophotometric DNA quantification on a Synergy HT multi-mode microplate reader (BioTek Instruments, Inc., Vermont, USA), using a Take3 micro-volume plate accessory. DNA content was determined using the nucleic acid quantification protocol with sample type defined for double-strand DNA in the Gen5 data analysis software version 2.01 (BioTek Instruments, Inc., Vermont, USA).

\subsection{Target gene selection and oligonucleotide primers}

For each locus, ITS1 and matK, sequences from $H$. perforatum and $H$. androsaemum were retrieved from the NCBI database, with the accession numbers presented in Table 1 . In each locus, one set of 
Table 1

Oligonucleotide primers used for the amplification of Hypericum spp.

\begin{tabular}{|c|c|c|c|c|}
\hline Target & Primers & Sequence $\left(5^{\prime} \rightarrow 3^{\prime}\right)$ & Amplicons (bp) & Reference or GenBank accession no. \\
\hline \multicolumn{5}{|l|}{ ITS1 sequencing } \\
\hline H. androsaemum/ & ITS1-F & TGAACCTGCGGAAGGATCATT & $297 / 298$ & AY573012.1/ \\
\hline H. perforatum & ITS1-R & AGATATCCGTTGCCGAGAGT & & EU796888.1 \\
\hline \multicolumn{5}{|l|}{ ITS1 species-specific } \\
\hline \multirow[t]{2}{*}{ H. androsaemum } & HA-ITS1-F2 & TTTATCCCCGTAACCCCCGTG & 116 & This work \\
\hline & HA-ITS1-R2 & AGGTTCCTTGGCGCGTGCC & & \\
\hline \multirow[t]{2}{*}{ H. perforatum } & FO2 & CATAAGAAGTGTAAGGCTCCCGG & 85 & Crockett et al. (2004) \\
\hline & HRI-S & AGAGTCGTTATTGTTATGAACAGAAGGAG & & \\
\hline \multicolumn{5}{|l|}{ matK sequencing } \\
\hline H. androsaemum/ & matK-F & ATCCAACCATTTTCGGGTTC & 358 & HM850934/ \\
\hline H. perforatum & matK-R & TCGTATCGCTGAAGGAGTGA & & HQ331618 \\
\hline \multicolumn{5}{|l|}{ matK species-specific } \\
\hline \multirow[t]{2}{*}{ H. androsaemum } & HA-matK-F1 & TACTATAGAGTTGTTCAAGGACCC & 92 & This work \\
\hline & HA-matK-R1 & TCATTAAAAGTGGCGTACTCCTG & & \\
\hline \multirow[t]{2}{*}{ H. perforatum } & HP-matK-F1 & TTAATATACAGTTGTTCAAGGACC & 92 & This work \\
\hline & HP-matK-R1 & CATTATAAGTGGCGTACTCCTT & & \\
\hline
\end{tabular}

primers was firstly designed to produce amplicons with adequate size to allow the sequencing of Hypericum genus ( $H$. perforatum and $H$. androsaemum). After sequencing, new primers were specifically designed for each species in order to enable their unequivocal identification. All primers were synthesised by Eurofins MWG Operon (Ebersberg, Germany).

\subsection{Qualitative PCR}

For sequencing ITS1 and matK loci, PCR amplifications were carried out in $25 \mu \mathrm{L}$ of total reaction volume, containing $2 \mu \mathrm{L}$ of DNA extract (20 ng), $67 \mathrm{mM}$ of Tris- $\mathrm{HCl}$ (pH 8.8), $16 \mathrm{mM}$ of $\left(\mathrm{NH}_{4}\right)_{2} \mathrm{SO}_{4}$, $0.01 \%$ of Tween $20,200 \mu \mathrm{M}$ of each dNTP, $1.0 \mathrm{U}$ of SuperHot Taq DNA Polymerase (Genaxxon Bioscience, Ulm, Germany), $1.5 \mathrm{mM}$ or $2.5 \mathrm{mM}$ (only for HA-ITS1-F2/HA-ITS1-R2 primers) of $\mathrm{MgCl}_{2}$ and $100 \mathrm{nM}$ (ITS1-F/ITS1-R and matK-F/matK-R) or $200 \mathrm{nM}$ (HA-matKF1/HA-matK-R1, HP-matK-F1/HP-matK-R1, HA-ITS1-F2/HA-ITS1R2 and FO2/HRI-S) of each primer (Table 1). The reactions were performed in a MJ Mini thermal cycler (BioRad, Hercules, CA, USA).

For sequencing primers, the following program was used: initial denaturation at $95^{\circ} \mathrm{C}$ for $5 \mathrm{~min}$; 40 cycles at $95^{\circ} \mathrm{C}$ for $30 \mathrm{~s}, 61^{\circ} \mathrm{C}$ or $59{ }^{\circ} \mathrm{C}$ for $45 \mathrm{~s}$ and $72{ }^{\circ} \mathrm{C}$ for $1 \mathrm{~min}$, respectively for primers ITS1-F/ ITS1-R or matK-F/matK-R (Table 1 ); and a final extension at $72{ }^{\circ} \mathrm{C}$ for $5 \mathrm{~min}$. The other PCR amplifications were performed using the following programs: initial denaturation at $95{ }^{\circ} \mathrm{C}$ for $5 \mathrm{~min} ; 40$ cycles at $95{ }^{\circ} \mathrm{C}$ for $30 \mathrm{~s}, 65{ }^{\circ} \mathrm{C}, 64{ }^{\circ} \mathrm{C}, 62{ }^{\circ} \mathrm{C}$ or $59{ }^{\circ} \mathrm{C}$ for $30 \mathrm{~s}$, respectively for primers FO2/HRI-S, HA-ITS1-F2/HA-ITS1-R2, HAmatK-F1/HA-matK-R1, or HP-matK-F1/HP-matK-R1 (Table 1), and $72{ }^{\circ} \mathrm{C}$ for $30 \mathrm{~s}$, with a final extension at $72{ }^{\circ} \mathrm{C}$ for $5 \mathrm{~min}$.

The amplified fragments were analysed by electrophoresis in 1.5\% agarose gel containing $1 \times$ Gel Red (Biotium, CA, USA) for staining and carried out in $1 \times$ SGTB buffer (GRISP, Porto, Portugal) for about $20-25 \mathrm{~min}$ at $200 \mathrm{~V}$. The agarose gel was visualised under a UV light tray Gel Doc ${ }^{\mathrm{TM}}$ EZ System (BioRad Laboratories, Hercules, CA, USA) and a digital image was obtained with Image Lab software version 5.1 (BioRad Laboratories, Hercules, CA, USA).

\subsection{Real-time PCR and HRM analysis}

The real-time PCR assays were carried out in $20 \mu \mathrm{L}$ of total reaction volume, containing $2 \mu \mathrm{L}$ of DNA (20 ng), $1 \mathrm{x}$ of SsoFast ${ }^{\mathrm{TM}}$ Evagreen ${ }^{\circledR}$ Supermix (Bio-Rad Laboratories, Hercules, CA, USA) and $250 \mathrm{nM}$ of each primer (Table 1). The reactions were performed in a fluorometric thermal cycler CFX96 Real-time PCR Detection System (Bio-Rad Laboratories, Hercules, CA, USA) using the following conditions: $95{ }^{\circ} \mathrm{C}$ for $5 \mathrm{~min}$; 50 cycles at $95{ }^{\circ} \mathrm{C}$ for $10 \mathrm{~s}$ and $65^{\circ} \mathrm{C}$,
$64{ }^{\circ} \mathrm{C}, 62^{\circ} \mathrm{C}$ or $59{ }^{\circ} \mathrm{C}$ for $30 \mathrm{~s}$, for primers FO2/HRI-S, HA-ITS1-F2/ HA-ITS1-R2, HA-matK-F1/HA-matK-R1 or HP-matK-F1/HP-matK$R 1$, respectively (Table 1 ). The collection of fluorescence signal was performed at the end of each cycle and data were processed using the software Bio-Rad CFX Manager 3.1 (Bio-Rad Laboratories, Hercules, CA, USA).

For HRM analysis, PCR products were denatured at $95{ }^{\circ} \mathrm{C}$ for $1 \mathrm{~min}$ and then annealed at $65^{\circ} \mathrm{C}, 64^{\circ} \mathrm{C}, 62^{\circ} \mathrm{C}$ or $59^{\circ} \mathrm{C}$ for $3 \mathrm{~min}$, for primers FO2/HRI-S, HA-ITS1-F2/HA-ITS1-R2, HA-matK-F1/HAmatK-R1 or HP-matK-F1/HP-matK-R1, respectively, in order to allow the correct annealing of the DNA duplexes. These two steps were followed by melting curve ranging up to $95{ }^{\circ} \mathrm{C}$ with temperature increments of $0.02{ }^{\circ} \mathrm{C} / \mathrm{s}$. The fluorescence data were acquired at the end of each melting temperature and further processed using the Precision Melt Analysis Software 1.2 (Bio-Rad Laboratories, Hercules, CA, USA) to generate melting curves as a function of temperature and difference curves for easier visual identification of clusters. Melting curve shape sensitivity determines the stringency used to classify melting curves into different clusters, while temperature of melting $(\mathrm{Tm})$ difference threshold is a parameter that determines the lowest amount of Tm difference between samples. In both cases, cluster detection parameters were set to high sensitivity and threshold yields aiming at providing more heterozygote clusters. Therefore, melting curve shape sensitivity was adjusted as a default value of $50 \%$ and Tm difference threshold was set as 0.20 .

DNA extracts of voucher seeds and herbal infusions were analysed in replicates $(n=3)$ in two independent assays.

\subsection{Sequencing of $P C R$ products}

PCR products of $H$. androsaemum and $H$. perforatum amplified with ITS1-F/ITS1-R and matK-F/matK-R were purified with Jetquick PCR purification kit (Genomed, Löhne, Germany) to remove any possible interfering components. The purified products were sent to a specialised research facility (STABVIDA, Lisbon, Portugal) for sequencing. Each target fragment was sequenced twice, performing the direct sequencing of both strands in opposite directions, which allowed the production of two complementary sequences of high quality.

\section{Results and discussion}

DNA barcoding has been recently advanced as a widely used and effective tool for the rapid and accurate identification/differentiation of species (Li et al., 2015). Although the cytochrome oxidase I 

H. androsaemum AY573012.1
H. androsaemum 1
H. androsaemum 2
H. perforatum EU796888.1
H. perforatum 1
H. perforatum 2
H. perforatum 3

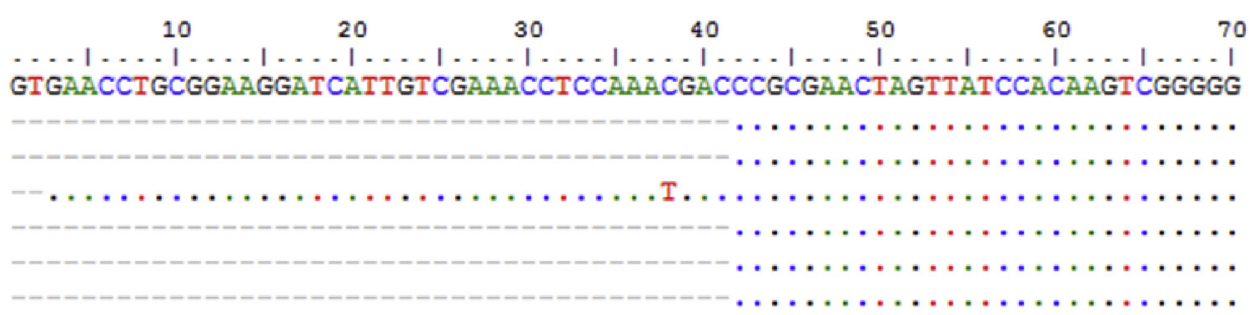

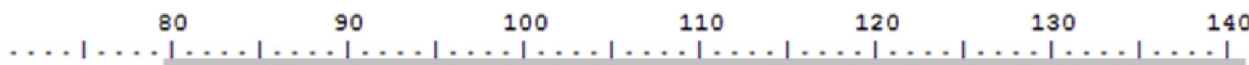
TGIC---GGTTTAT-CCCCGTAACCCCCGTGCGCCGGTGGTGGCCATGCGAGCCGATCTCTCGGCACGGG

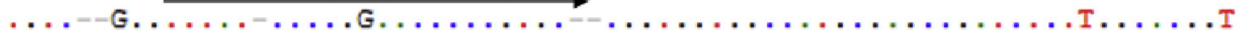

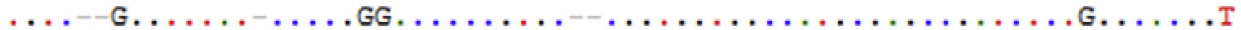
...GTG..C..C.GT...GCG.....G. .......................

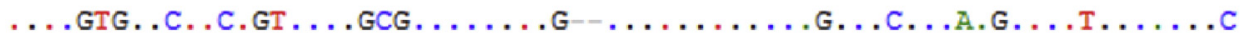
...GTG.C..C.GT...GCG......G-...................... ...GIG..C..C.GT...GCG.....GG-......................

\author{
H. androsaemum AY573012.1 \\ H. androsaemum 1 \\ H. androsaemum 2 \\ H. perforatum EU796888.1 \\ H. perforatum 1 \\ H. perforatum 2 \\ H. perforatum 3
}

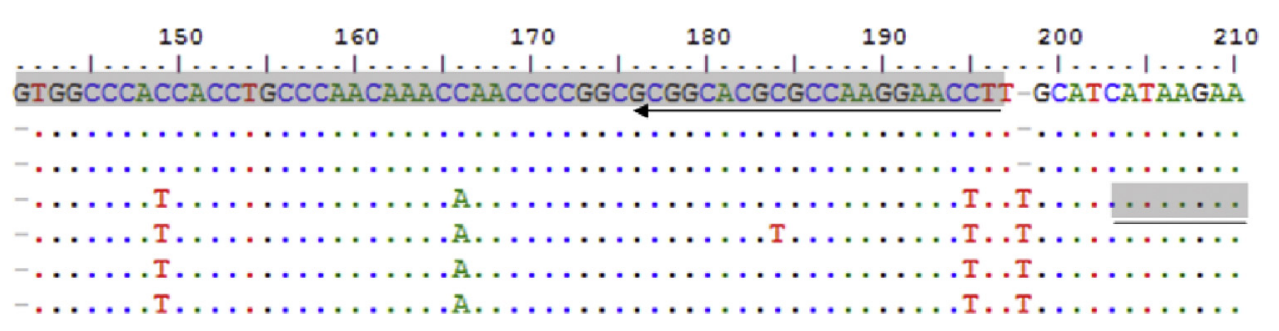

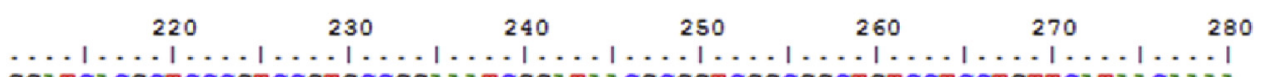
GGATCACGCTCCCGTCCGTGCCGGAAATCGGATAACGCGGTCGGCGGCTGTCCTCCTGTTCATAACAAAA.

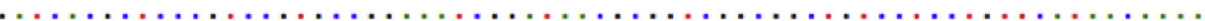

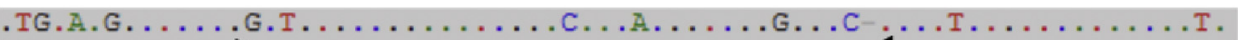

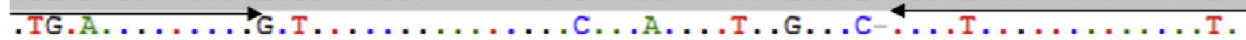

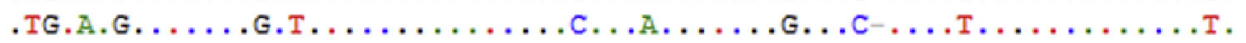
.TG.A.G.....G.T..........................T.........

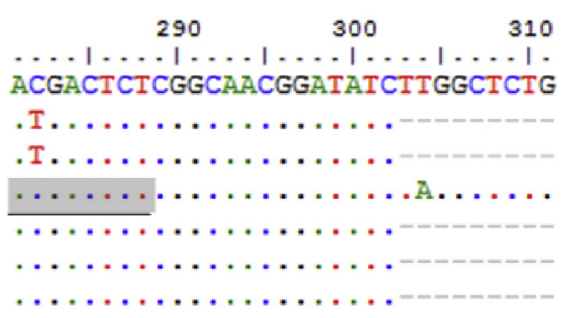

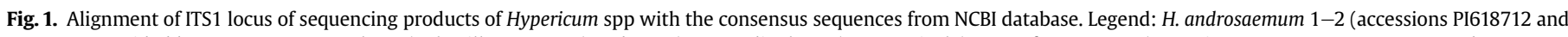

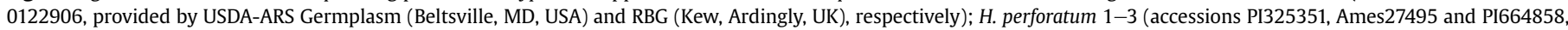
respectively provided by USDA-ARS Germplasm (Beltsville, MD, USA)).

(COI) has been recommended as the universal DNA barcode for animal identification (http://www.barcodeoflife.org), the same region DNA region is not suitable for plants (Kress, Wurdack, Zimmer, Weigt, \& Janzen, 2005). From numerous available loci, none works across all plant species, thus disabling their universal identification. So far, several plastidial and mitochondrial genes have been evaluated, but there is still no consensual opinion concerning the best candidate markers for plant DNA barcoding (Ferri et al., 2015). Presently, a multi-locus approach, combining the identification of noncoding intergenic spacers (e.g. ITS, trnH-psbA) and plastidial coding sequences (e.g. matK, $r b c \mathrm{~L}$ ), is considered the best option for the correct differentiation of plant species (Selvaraj et al., 2013).
Among them, two DNA regions, namely the matK and the rbcL genes, have been approved as excellent plant DNA barcodes. In addition to plastid genome, the internal transcribed spacer, which is flanked by the coding sequence of $18 \mathrm{~S}$ and $5.8 \mathrm{~S}$ rRNA or $5.8 \mathrm{~S}$ and $28 \mathrm{~S}$ rRNA, respectively for ITS1 and ITS2, has also been classified as potential barcode regions (Howard et al., 2009).

In the present work, based on the available information regarding DNA barcoding of plants, aiming at identifying the botanical origin of different species of Hypericum, namely the $H$. perforatum and the $H$. androsaemum, two genomic regions were selected: the ITS1 that is considered a powerful phylogenetic marker for species with high levels of interspecific divergence; and 


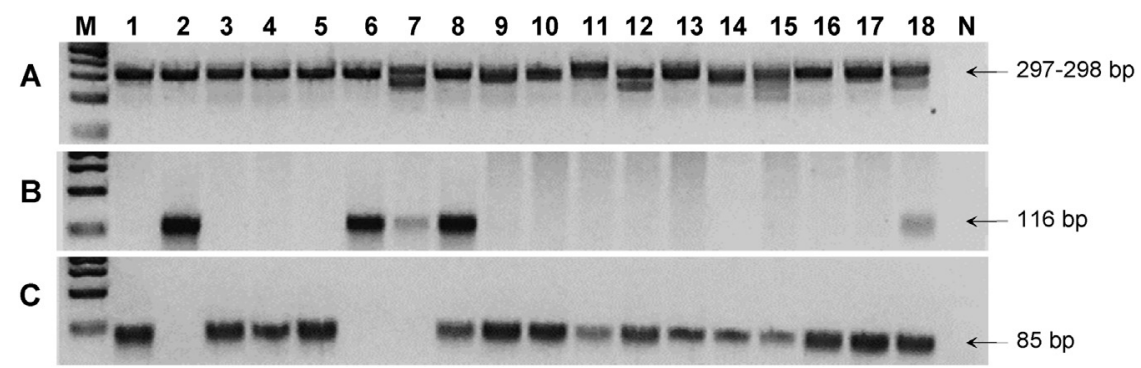

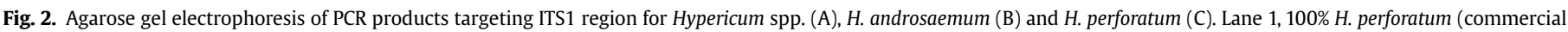

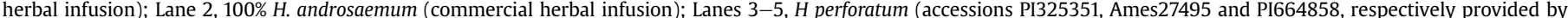

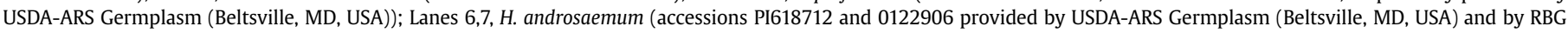

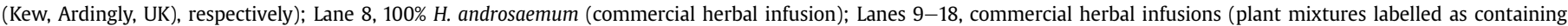
H. perforatum)

the plastidial gene matK, which has a high evolutionary rate, suitable length, interspecific divergence and a low transition/transversion rate (Li et al., 2015).

The quality assessment of DNA extracts from plant material (herbal infusions and other medicinal plants) showed adequate yields $(89-355 \mathrm{ng} / \mu \mathrm{L})$ and purities $(1.8 \pm 0.2)$. The extracts from seeds exhibited low DNA yield $(<5 \mathrm{ng} / \mu \mathrm{L})$, but with good purities $(1.9 \pm 0.2)$. These results could be related to the rigid nature of the material (seed casing) that was probably hampering the access to DNA during the extraction procedure. In order to assess amplifiability, DNA extracts were also tested with universal eukaryotic primers 18SRG-F/18SRG-R as described by Costa, Oliveira, and
Mafra (2013), exhibiting positive amplification for all samples (data not shown), thus confirming the absence of any false negative results.

\subsection{ITS1 locus}

\subsubsection{Sequencing}

ITS1 locus from five Germplasm seeds (three samples of $H$. perforatum and two samples of $H$. androsaemum) were amplified as voucher species using specific primers targeting the Hypericum genus. Each PCR product was amplified with direct sequencing of both strands in opposite directions. Considering that the platform

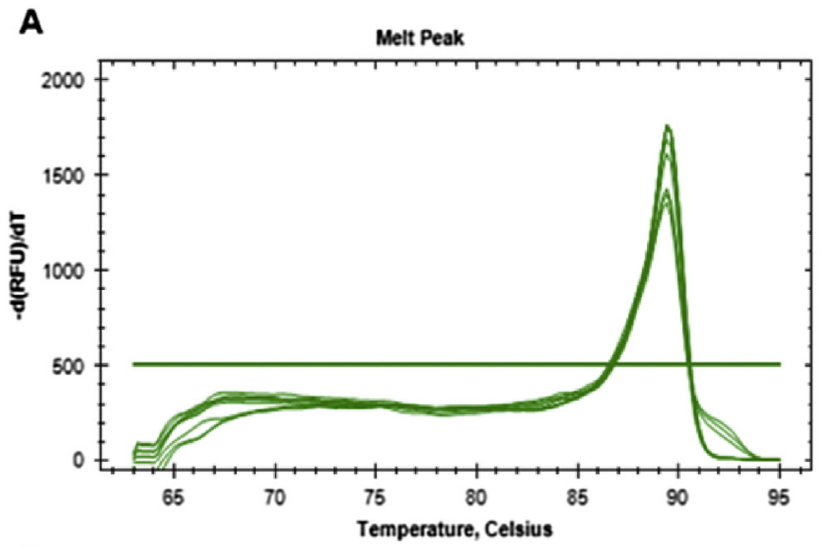

B
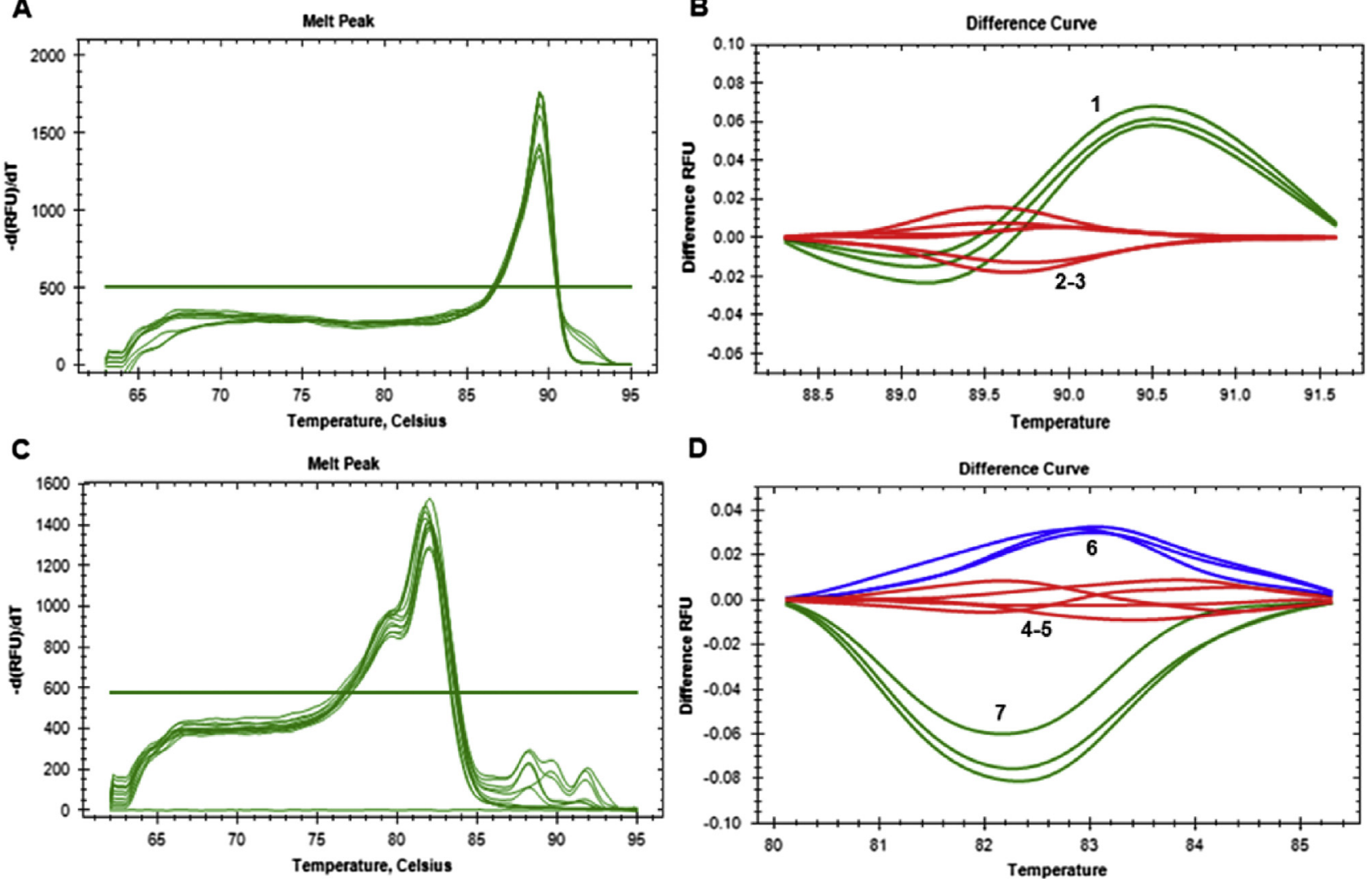

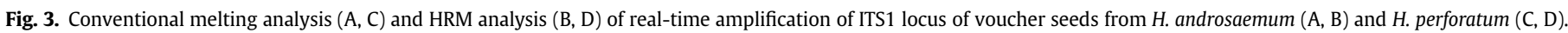

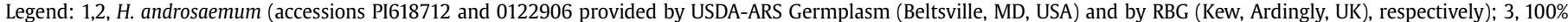

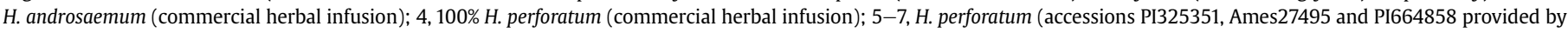
USDA-ARS Germplasm (Beltsville, MD, USA), respectively). 

H. androsaemum HQ331618.1
H. androsaemum 1
H. androsaemum 2
H. perforatum HM850934.1
H. perforatum 1
H. perforatum 2
H. perforatum 3

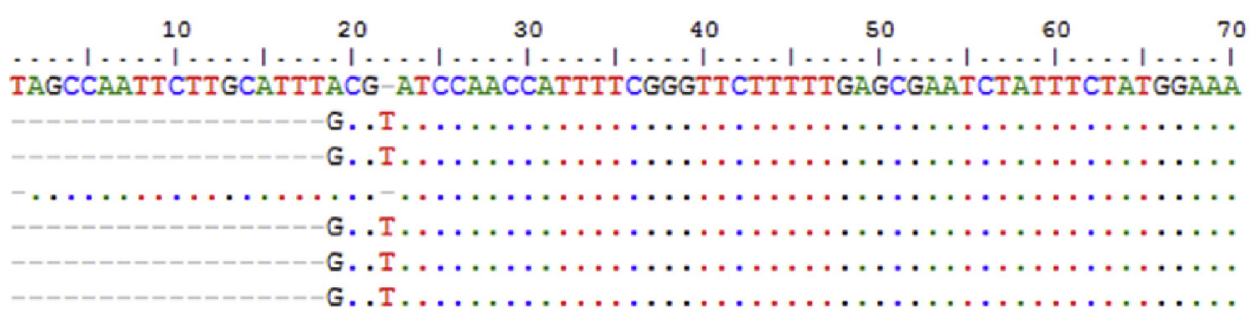

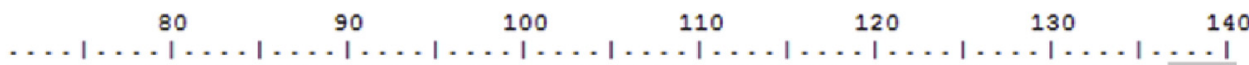
AGTAGAGALTTTACAGAAGTTTTTGCTAAGAAGTTIATAGATGTTTTTGCTAATAGTTTTCAAGTTACT

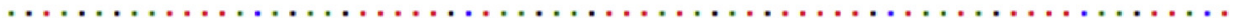

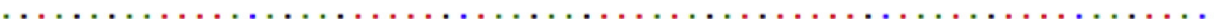
$\ldots \ldots$. $\ldots \ldots \ldots \ldots \ldots \ldots \ldots \ldots \ldots \ldots \ldots \ldots \ldots \ldots \ldots \ldots$.. .

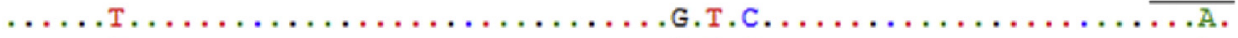

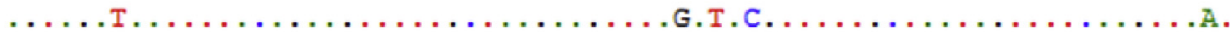
$\ldots \ldots$. . . . . . . . . . . . . .

\section{H. androsaemum $\mathrm{HQ331618.1}$ \\ H. androsaemum 1 \\ H. androsaemum 2 \\ H. perforatum HM850934.1 \\ H. perforatum 1 \\ H. perforatum 2 \\ H. perforatum 3}

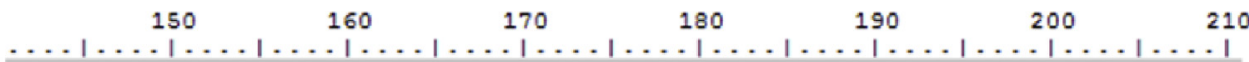

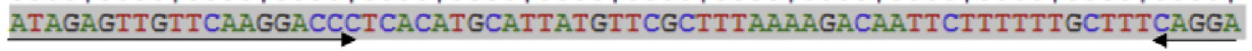

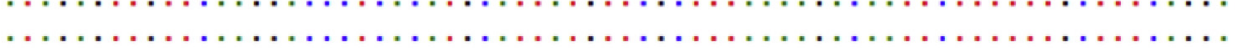

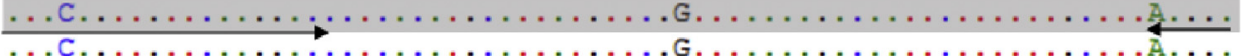

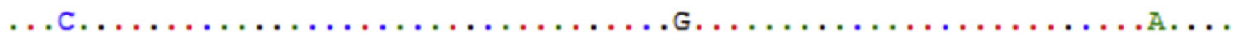

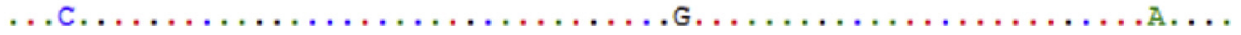

\author{
H. androsaemum HQ331618.1 \\ H. androsaemum 1 \\ H. androsaemum 2 \\ H. perforatum HM850934.1 \\ H. perforatum 1 \\ H. perforatum 2 \\ H. perforatum 3
}

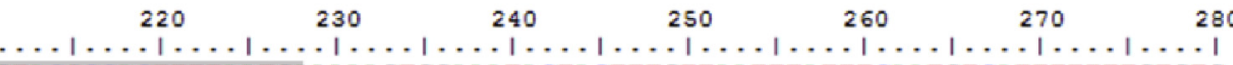
GTACGCCACTTTTAATGAAAAAGTGGAAATACTACTTTGTTAATTTATTTCAATGTCATTTTTTTGTGTG

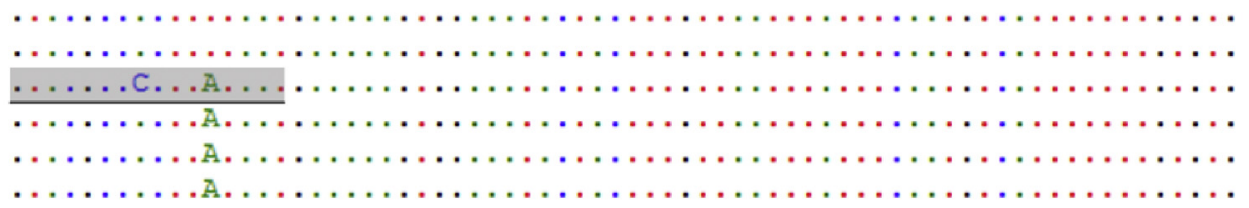

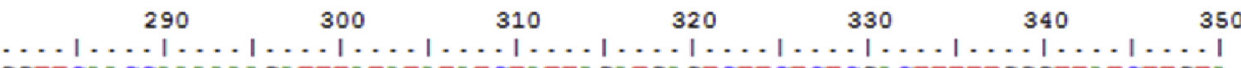
GGTTCAACCAAAAAAGATTTATATATATCTATTAGATGAGTCTTCTCTCGACTTTTTGGGTTATCTTGTA

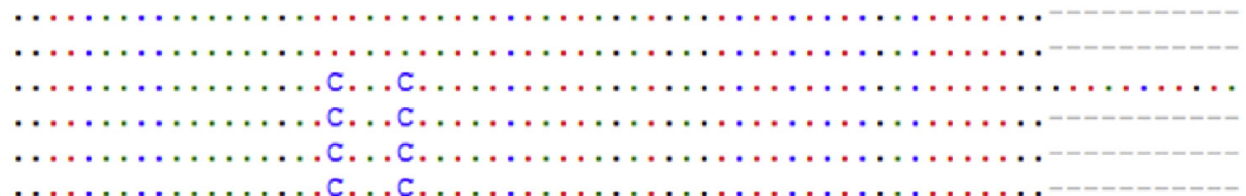

\section{H. androsaemum HQ331618.1 \\ H. androsaemum 1 \\ H. androsaemum 2 \\ H. perforatum HM850934.1 \\ H. perforatum 1 \\ H. perforatum 2 \\ H. perforatum 3}

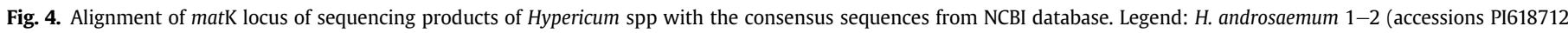

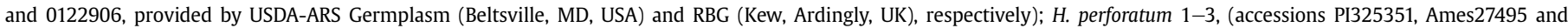
PI664858, respectively provided by USDA-ARS Germplasm (Beltsville, MD, USA)).

often does not allow perfect resolution for the reading of the first $\sim 50 \mathrm{bp}$ at the 5 '-end of the sequence, data on Fig. 1 refers to sequencing of 258 bp with double coverage. The sequences revealed some nucleotide variability among voucher seeds from the same species, evidencing high intra-species variability that is often attributed to this noncoding DNA region (internal transcribed spacer). In spite of such variability, $H$. androsaemum exhibited several nucleotide differences from $H$. perforatum, which can be observed in Fig. 1. Using the sequencing data, a new pair of primers was specifically designed for $H$. androsaemum targeting an amplicon of $116 \mathrm{bp}$. For $H$. perforatum, primers targeting the same region were already available in the literature (Crockett, Douglas, Scheffler,
\& Khan, 2004), thus being selected for its specific amplification (Table 1, Fig. 1).

\subsubsection{Qualitative PCR}

Cross-reactivity assays were performed for each set of primers targeting ITS1 locus (HA-ITS1-F2/HA-ITS1-R2 and FO2/HRI-S), using different plant species (medicinal and foods, $n=37$ ) and the Hypericum species under study $(H$. androsaemum and H. perforatum). In both cases, no cross-reactivity was found with any of the medicinal plants, being the reactions specific for each intended target species (data not shown).

Along with voucher species, herbal infusions $(n=13)$ were also 


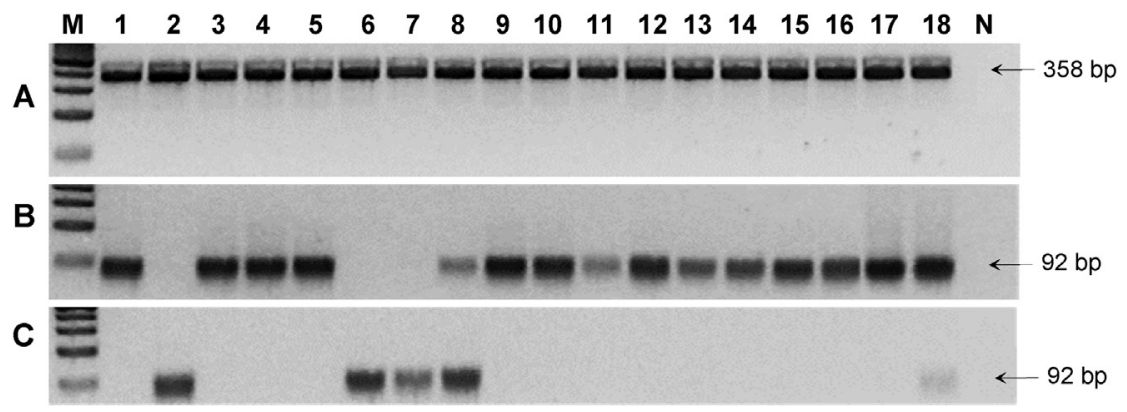

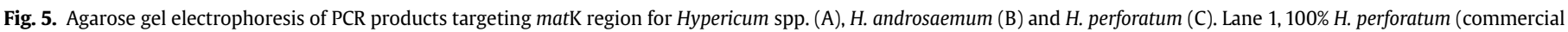

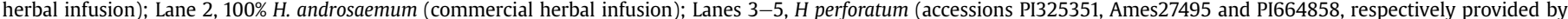

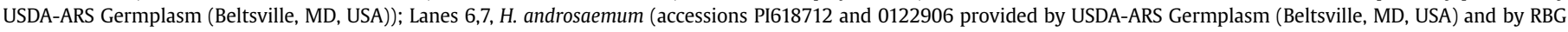

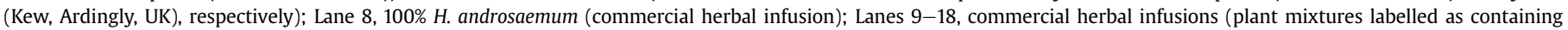
H. perforatum).

successfully amplified by qualitative PCR targeting Hypericum spp. (Fig. 2A) and each species, $H$. androsaemum (Fig. 2B) and $H$. perforatum (Fig. 2C). From the obtained results, two nonconformities were found in commercial samples after verifying labelling compliance. Sample in lane 8 was labelled as $100 \%$ $H$. androsaemum, but it also amplified positively for $H$. perforatum
(Fig. 2B, C), which suggests the partial substitution of the first species by the second one in this herbal infusion. Sample in lane 18 is labelled as containing $H$. perforatum, though it also presented a faint band for $H$. androsaemum (Fig. 2B, C), suggesting in this case the eventual cross-contamination during manipulation and/or packaging.
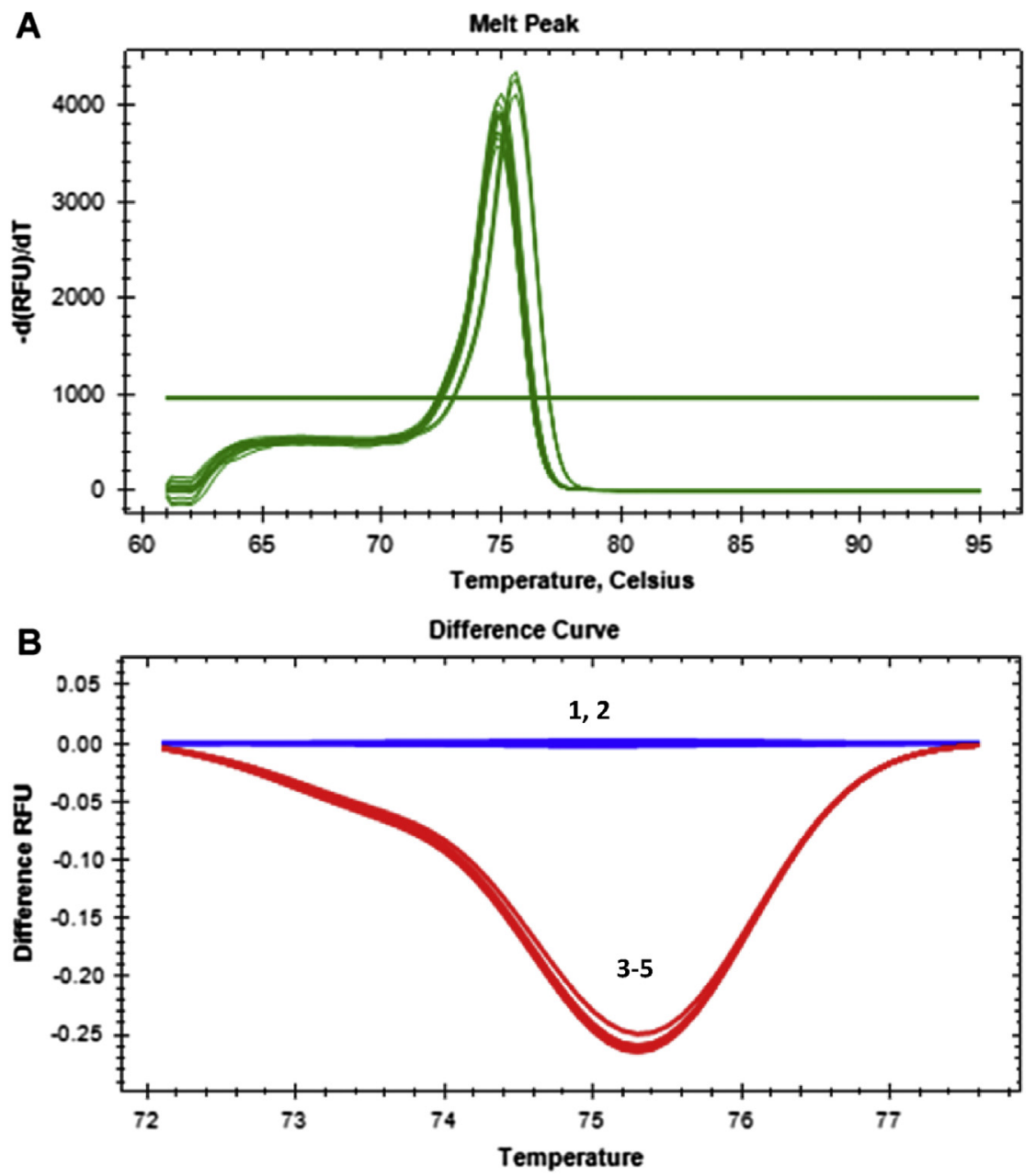

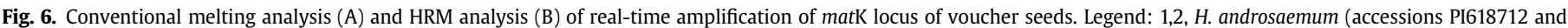

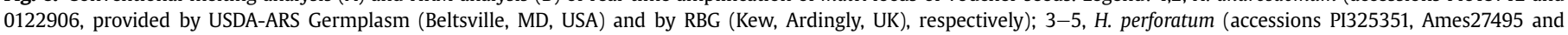
PI664858, respectively provided by USDA-ARS Germplasm (Beltsville, MD, USA)), using specific primers for each species in single assay. 


\subsubsection{Real-time PCR coupled with HRM analysis}

Owing to the intra-species variability of the ITS1 region, DNA from voucher species was evaluated by real-time PCR using EvaGreen as a fluorescent dye, targeting each species (H. androsaemum or H. perforatum). In the case of H. androsaemum, real-time PCR assays enabled to confirm the results from qualitative PCR (Fig. 3), evidencing a temperature of melting of approximately $89.6{ }^{\circ} \mathrm{C}$ (Fig. 3A). However, when performing HRM analysis, two distinct clusters were defined with high level of confidence ( $>98.8 \%$ ). HRM analysis included one voucher species (accession no. 0122906) and the herbal infusion containing 100\% $H$. androsaemum in cluster 1 (reference cluster), while the second voucher (accession no. PI618712) was comprised in cluster 2 (Fig. 3B).

Real-time PCR trials targeting $H$. perforatum also confirmed the results obtained by qualitative PCR. Conventional melting allowed the identification of a main melt pick of approximately $82.0^{\circ} \mathrm{C}$ and a small pick at $79.6{ }^{\circ} \mathrm{C}$ (Fig. 3C). After HRM analysis, PCR products were included in three distinct groups. The voucher seeds $(n=3)$ were comprised in three different clusters (Fig. 3D) with a level of confidence above $98.0 \%$. Since HRM analysis is based on minute differences within amplicon size and/or composition, a simple nucleotide difference could be enough to differentiate two identical sequences. Owing to this principle, different clusters were created by covering products that should present similar size and composition. Although HRM analysis is mainly used as a high-throughput approach for the rapid differentiation of species on the basis of highly similar sequences (Costa, Mafra, \& Oliveira, 2012; Osathanunkul, Madesis, \& de Boer, 2015), in this work HRM was applied as a confirmatory tool for the evaluation of ITS1 as DNA mini-barcode. For both Hypericum species, the results of HRM analysis could be explained by the high intra-species variability of ITS1 region among individuals, which can be highlighted by sequencing (Fig. 1). The results concerning $H$. perforatum are in good agreement with the work described by Howard et al. (2009) since the primers targeting the referred species were designed on a region of considerable sequence diversity.

\section{2. matK locus}

\subsubsection{Sequencing}

Following the multi-locus approach, the plastidial matK gene was carefully chosen as a second DNA barcode for the identification of Hypericum species. Using voucher seeds, PCR amplification was carried out targeting a 358 bp region of matK gene and the respective sequencing results are presented in Fig. 4. It refers to a complete and correct sequencing of 320 bp products with double coverage. Contrarily to ITS1 locus, sequencing products of matK did not present variability among accessions of the same species. Accordingly, new primers producing amplicons of 92 bp were specifically designed targeting each Hypericum species (Table 1 , Fig. 4). In both cases, each set of primers included a total of 4 nucleotide mismatches, aiming at conferring high specificity to the PCR systems (Fig. 4).

\subsubsection{Qualitative $P C R$}

Assays testing the specificity of each set of designed primers targeting the matK region were also performed (HA-matK-F1/HAmatK-R1 and HP-matK-F1/HP-matK-R1). Each pair of primers was specific for the corresponding Hypericum species target and no cross-reactivity was observed with other medicinal plants $(n=37)$ (data not shown).

The application of PCR assays was performed using the voucher species and herbal infusions targeting Hypericum spp. (Fig. 5A) and each of the species, $H$. androsaemum (Fig. 5B) and $H$. perforatum (Fig. 5C). From these results, the two previously found nonconformities in commercial samples 8 and 18 were also identified (Fig. 5B, C), thus confirming the results obtained from ITS1 locus amplification.

\subsubsection{Real-time PCR coupled with HRM analysis}

Results from real-time PCR trials were in good accordance with qualitative PCR results. By conventional melting analysis, amplicons evidenced good resolution with single melt peaks for each target, namely at $75.8{ }^{\circ} \mathrm{C}$ or $75.0{ }^{\circ} \mathrm{C}$ for $H$. androsaemum or $H$. perforatum (Fig. 6A), respectively. In a single assay, voucher seeds from the two

Table 2

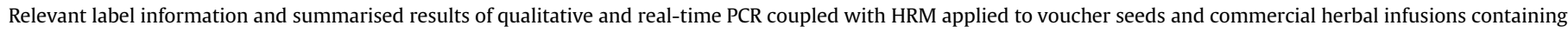
H. perforatum or $H$. androsaemum.

\begin{tabular}{|c|c|c|c|c|c|c|}
\hline \multirow[t]{2}{*}{ Samples } & \multicolumn{2}{|c|}{ Species declared in label } & \multicolumn{2}{|c|}{ H. perforatum } & \multicolumn{2}{|c|}{ H. androsaemum } \\
\hline & H. perforatum & H. androsaemum & PCR results & HRM (\% of confidence $\pm \mathrm{SD}^{\mathrm{d}}$ ) & PCR results & HRM (\% of confidence $\pm \mathrm{SD}^{\mathrm{d}}$ ) \\
\hline 1 & $\mathrm{X}$ & & + & $99.3 \pm 0.2$ & - & \\
\hline 2 & & $\mathrm{X}$ & - & & + & $98.7 \pm 0.4$ \\
\hline 3 & $\mathrm{X}^{\mathrm{a}}$ & & + & $99.9 \pm 0.0$ & - & \\
\hline 4 & $\mathrm{X}^{\mathrm{b}}$ & & + & $99.5 \pm 0.2$ & - & \\
\hline 5 & $\mathrm{X}^{\mathrm{a}}$ & & + & $99.9 \pm 0.1$ & - & \\
\hline 6 & & $X^{a}$ & - & & + & $99.9 \pm 0.1$ \\
\hline 7 & & $X^{a}$ & - & & + & $99.8 \pm 0.2$ \\
\hline 8 & $\mathrm{X}$ & & + & $98.5 \pm 0.1$ & + & $99.1 \pm 0.5$ \\
\hline 9 & $\mathrm{X}$ & & + & $99.8 \pm 0.1$ & - & \\
\hline 10 & $\mathrm{X}^{\mathrm{c}}$ & & + & $99.7 \pm 0.1$ & - & \\
\hline 11 & $\mathrm{X}$ & & + & $98.9 \pm 0.2$ & - & \\
\hline 12 & $X$ & & + & $99.7 \pm 0.1$ & - & \\
\hline 13 & $\mathrm{X}$ & & + & $99.7 \pm 0.3$ & - & \\
\hline 14 & $\mathrm{X}$ & & + & $99.8 \pm 0.1$ & - & \\
\hline 15 & $X$ & & + & $99.9 \pm 0.1$ & - & \\
\hline 16 & $\mathrm{X}$ & & + & $99.8 \pm 0.2$ & - & \\
\hline 17 & $\mathrm{X}^{\mathrm{c}}$ & & + & $99.5 \pm 0.3$ & - & \\
\hline 18 & $X$ & & + & $99.5 \pm 0.4$ & + & $98.9 \pm 0.1$ \\
\hline
\end{tabular}

\footnotetext{
${ }^{a}$ Voucher seeds provided by USDA-ARS Germplasm (Beltsville, MD, USA) and by

b RBG (Kew, Ardingly, UK).

c Labels state the presence of "Hipericão" without specifying Hypericum species.

d Mean of \% of confidence \pm standard deviation.
} 
Hypericum species were amplified using the correspondent set of primers. In spite of presenting very similar melt peaks, HRM analysis allowed discriminating $H$. perforatum and $H$. androsaemum in clusters 1 and 2 (Fig. 6B), respectively, with high level of confidence (>99.5\%).

HRM analysis was further applied to commercial herbal infusions, enabling their authentication regarding the presence of Hypericum species. Table 2 presents the summary of relevant information concerning qualitative and real-time PCR coupled with HRM analysis. The obtained results were then compared with information on the labels and the two non-conformities observed by qualitative PCR were confirmed. HRM analysis allowed identifying $H$. androsaemum in sample 8 with $99.1 \%$ of confidence, which is in accordance with the labelled information of $100 \% \mathrm{H}$. androsaemum (Table 2). However, in the same sample, HRM analysis also detected $H$. perforatum with a level of confidence of $98.5 \%$, thus confirming previous findings. The same pattern was observed for sample 18 , in which both Hypericum species (H. androsaemum and H. perforatum) were identified with high level of confidence (98.9\% and $99.5 \%$, respectively).

\section{Conclusion}

In this work, two DNA mini-barcode regions (ITS1 and matK) were proposed for the differentiation of Hypericum species, namely $H$. androsaemum or $H$. perforatum. Species-specific PCR assays were successfully developed for both ITS1 and matK regions, revealing its adequacy as simple and fast approaches for species identification. Both regions were also proposed for the development of real-time PCR assays coupled to HRM analysis. However, ITS1 region revealed some intra-species variability from sequencing results, which compromises HRM analysis. Conversely, matK showed to be an adequate mini-barcode region for the differentiation of both species by real-time PCR coupled to HRM analysis. All PCR systems were effectively applied to commercial herbal infusions, enabling the consistent identification of two labels with non-declared Hypericum species. Herein, simple, fast, reliable, cost-effective and high throughput approaches have been proposed for the authentication of herbal infusions.

\section{Acknowledgements}

This work received financial support from the European Union (FEDER funds through COMPETE) and National Funds (FCT, Fundação para a Ciência e Tecnologia) through project EXPL/DTPSAP/1438/2013 (4SaferPFS - Safety of plant food supplements: searching for adulterant pharmaceutical drugs and plants) and UID/ QUI/50006/2013. Joana Costa is grateful to FCT grant (SFRH/BPD/ 102404/2014) financed by POPH-QREN (subsidised by FSE and MCTES). The authors are grateful for the supply of voucher seeds by USDA-ARS Germplasm (Beltsville, MD, USA) and by RBG (Kew, Ardingly, UK).

\section{References}

Almeida, I. F., Fernandes, E., Lima, J. L. F. C., Costa, P. C., \& Bahia, M. F. (2009). In vitro protective effect of Hypericum androsaemum extract against oxygen and nitrogen reactive species. Basic \& Clinical Pharmacology \& Toxicology, 105, 222-227.

Büter, B., Orlacchio, C., Soldati, A., \& Berger, K. (1998). Significance of genetic and environmental aspects in the field cultivation of Hypericum perforatum. Planta Medica, 64, 431-437.

Butterweck, V., Petereit, F., Winterhoff, H., \& Nahrstedt, A. (1998). Solubilized hypericin and pseudohypericin from Hypericum perforatum exert antidepressant activity in the forced swimming test. Planta Medica, 64, 291-294.

Butterweck, V., \& Schmidt, M. (2007). St. John's wort: role of active compounds for its mechanism of action and efficacy. Wiener Medizinische Wochenschrift, 157, 356-361.

Chen, S., Yao, H., Han, J., Liu, C., Song, J., Shi, L., et al. (2010). Validation of the ITS2 region as a novel DNA barcode for identifying medicinal plant species. PLoS One, 5(1), e8613.

Conforti, F., Statti, G. A., Tundis, R., Bianchi, A., Agrimonti, C., Sacchetti, G., et al. (2005). Comparative chemical composition and variability of biological activity of methanolic extracts from Hypericum perforatum L. Natural Product Research, 19(3), 295-303.

Costa, J., Mafra, I., \& Oliveira, M. B. P. P. (2012). High resolution melting analysis as a new approach to detect almond DNA encoding for Pru du 5 allergen in foods. Food Chemistry, 133, 1062-1069.

Costa, J., Melo, V. S., Santos, C. G., Oliveira, M. B. P. P., \& Mafra, I. (2015). Tracing tree nut allergens in chocolate: a comparison of DNA extraction protocols. Food Chemistry, 187, 469-476.

Costa, J., Oliveira, M. B. P. P. \& Mafra, I. (2013). Effect of thermal processing on the performance of the novel single-tube nested real-time PCR for the detection of walnut allergens in sponge cakes. Food Research International, 54, 1722-1729.

Crockett, S. L., Douglas, A. W., Scheffler, B. E., \& Khan, I. A. (2004). Genetic profiling of Hypericum (St. John's Wort) species by nuclear ribosomal ITS sequence analysis. Planta Medica, 70, 929-935.

Egan, B., Hodgkins, C., Shepherd, R., Timotijevic, L., \& Raats, M. (2011). An overview of consumer attitudes and beliefs about plant food supplements. Food and Function, 2, 747-752.

Ernst, E., \& Izzo, A. A. (2003). The clinical pharmacology of Hypericum perforatum. In E. Ernst (Ed.), Hypericum: The Genus Hypericum (Vol. 31, pp. 155-172). New York: Taylor's and Francis.

European Medicines Agency. (2009). Community herbal monograph on Hypericum perforatum L., Herba (well-established medicinal use). Available at: http://www. ema.europa.eu/docs/en_GB/document_library/Herbal_-_Community_herbal_ monograph/2010/01/WC500059149.pdf.

Ferri, G., Corradini, B., Ferrari, F., Santunione, A. L., Palazzoli, F., \& Alu', M. (2015), Forensic botany II, DNA barcode for land plants: which markers after the international agreement? Forensic Science International: Genetics, 15, 131-136.

Fields, A. T., Abercrombie, D. L., Eng, R., Feldheim, K., \& Chapman, D. D. (2015). A novel mini-DNA barcoding assay to identify processed fins from internationally protected shark species. PLoS One, 10(2), 1-10.

Franz, C., Chizzola, R., Novak, J., \& Sponza, S. (2011). Botanical species being used for manufacturing plant food supplements (PFS) and related products in the EU member states and selected third countries. Food \& Function, 2, 720-730.

Guedes, A. P., Franklin, G., \& Fernandes-Ferreira, M. (2012). Hypericum sp.: essential oil composition and biological activities. Phytochemistry Reviews, 11, 127-152.

Hajibabaei, M., \& McKenna, C. (2012). DNA mini-barcodes. In W. J. Kress, \& D. L. Erickson (Eds.), DNA barcodes (Vol. 858, pp. 339-353). New York: Humana Press.

Hebert, P. D. N., Cywinska, A., Ball, S. L., \& deWaard, J. R. (2003). Biological identification through DNA barcodes. Proceedings of the Royal Society B: Biological Sciences, 270(1512), 313-321.

Hosni, K., Msaâda, K., Taârit, M. B., Hammami, M., \& Marzouk, B. (2010). Bioactive components of three Hypericum species from Tunisia: a comparative study. Industrial Crops and Products, 31, 158-163.

Howard, C., Bremner, P. D., Fowler, M. R., Isodo, B., Scott, N. W., \& Slater, A. (2009). Molecular identification of Hypericum perforatum by PCR amplification of the ITS and 5.8S rDNA region. Planta Medica, 75, 864-869.

Kitanov, G. M. (2001). Hypericin and pseudohypericin in some Hypericum species. Biochemical Systematics and Ecology, 29, 171-178.

Kress, W. J., Wurdack, K. J., Zimmer, E. A., Weigt, L. A., \& Janzen, D. H. (2005). Use of DNA barcodes to identify flowering plants. Proceedings of the National Academy of Sciences of the United States of America, 102, 8369-8374.

Linde, K., Ramirez, G., Mulrow, C. D., Pauls, A., Weidenhammer, W., \& Melchart, D. (1996). St John's wort for depression-an overview and meta-analysis of randomised clinical trials. British Medicine Journal, 313, 253-258.

Little, D. P. (2014). A DNA mini-barcode for land plants. Molecular Ecology Resources, $14,437-446$.

Li, X., Yang, Y., Henry, R. J., Rossetto, M., Wang, Y. \& Chen, S. (2015). Plant DNA barcoding: from gene to genome. Biological Reviews, 90, 157-166.

Nahrstedt, A., \& Butterweck, V. (1997). Biologically active and other chemical constituents of the herb of Hypericum perforatum L. Pharmacopsychiatry, 30, 129-134.

Newmaster, S., Grguric, M., Shanmughanandhan, D., Ramalingam, S., \& Ragupathy, S. (2013). DNA barcoding detects contamination and substitution in North American herbal products. BMC Medicine, 11(1), 222.

Osathanunkul, M., Madesis, P., \& de Boer, H. (2015). Bar-HRM for authentication of plant-based medicines: evaluation of three medicinal products derived from Acanthaceae species. PLoS one, 10(5), e0128476.

Penso, G. (1983). Index plantarum medicinalium totius mundi eorumque synonymorum: INPLAMED. Milan: O. E. M. F.

Poutaraud, A., \& Girardin, P. (2004). Agronomic and chemical characterization of 39 Hypericum perforatum accessions between 1998 and 2000. Plant Breeding, 123. 480-484.

Russo, E., Scicchitano, F., Whalley, B. J., Mazzitello, C., Ciriaco, M., Esposito, S., et al. (2014). Hypericum perforatum: pharmacokinetic, mechanism of action, tolerability, and clinical drug-drug interactions. Phytotherapy Research, 28, 643-655.

Sarris, J. (2007). Herbal medicines in the treatment of psychiatric disorders: a systematic review. Phytotherapy Research, 21, 557-559.

Schrader, E., Meier, B., \& Brattstrom, A. (1998). Hypericum treatment of mildmoderate depression in a placebo controlled study: a prospective, doubleblind, randomized, placebo-controlled, multicentre study. Human 
Psychopharmacology, 13, 163-169.

Selvaraj, D., Park, J.-I., Chung, M.-Y., Cho, Y.-G., Ramalingam, S., \& Nou, I.-S. (2013). Utility of DNA barcoding for plant biodiversity conservation. Plant Breeding and Biotechnology, 1, 320-332.

Sucher, N. J., \& Carles, M. C. (2008). Genome-Based approaches to the authentication of medicinal plants. Planta Medica, 74, 603-623.

Techen, N., Parveen, I., Pan, Z., \& Khan, I. A. (2014). DNA barcoding of medicinal plant material for identification. Current Opinion in Biotechnology, 25, 103-110.

Valentão, P., Carvalho, M., Fernandes, E., Carvalho, F., Andrade, P. B., Seabra, R. M., et al. (2004). Protective activity of Hypericum androsaemum infusion against tert-butyl hydroperoxide-induced oxidative damage in isolated rat hepatocytes. Journal of Ethnopharmacology, 92, 79-84.
Valentão, P., Dias, A., Ferreira, M., Silva, B., Andrade, P. B., Bastos, M. L., et al. (2003). Variability in phenolic composition of Hypericum androsaemum. Natural Product Research, 17, 135-140.

Woelk, H. (2000). Comparison of St. John's wort and imipramine for treating depression: randomised controlled trial. British Medical Journal, 321, 536-539.

Xanthopoulou, A., Ganopoulos, I., Kalivas, A., Osathanunkul, M., Chatzopoulou, P. Tsaftaris, A., et al. (2016). Multiplex HRM analysis as a tool for rapid molecular authentication of nine herbal teas. Food Control, 60, 113-116.

Zhang, D., Yang, Y., Jiang, B., Lizhen, D., \& Zhou, N. (2014). How to correctly identify herbal materials in market: a case study based on DNA barcodes. African Journal of Traditional, Complementary and Alternative Medicines, 11, 66-76. 